\title{
Timing of Sexual Debut and Initiation of Postsecondary Education by Early Adulthood
}

\section{By Aubrey L. Spriggs and Carolyn Tucker Halpern}

Aubrey L. Spriggs is doctoral candidate,

Department of Maternal and Child Health, and predoctoral trainee, Carolina

Population Center, and Carolyn Tucker Halpern is associate professor, Department of Maternal and Child Health, and faculty fellow, Carolina Population Center, both at the University of North Carolina at Chapel Hill.
CONTEXT: Although sexual debut has been negatively associated with adolescent educational performance and aspirations, it is not clear whether such relationships continue beyond adolescence.

METHODS: Initiation of postsecondary education by young adulthood was assessed among 3,965 participants in the National Longitudinal Study of Adolescent Health who had not experienced sexual intercourse at baseline. Associations between age at sexual debut and educational progress were examined in bivariate and multivariable Poisson regression analyses.

RESULTS: Most respondents experienced sexual debut during adolescence: $15 \%$ before age 16 (early) and 53\% at ages 16-18 (typical). Sixty-five percent of respondents initiated postsecondary education by early adulthood; however, the proportion was significantly lower among those who had had an early (49\%) or typical sexual debut (63\%) than among those who debuted late (78\%). In unadjusted analyses, early and typical debut were associated with a reduced likelihood of initiation of postsecondary education for both females (relative risk ratios, 0.6 and 0.8, respectively) and males (0.7 and 0.8). However, in adjusted analyses, the associations were attenuated for females (0.8 and 0.9) and were at best marginally significant for males. Childbearing was a significant mediator of this relationship.

CONCLUSIONS: Adolescent sexual debut appears to be modestly negatively associated with early adult postsecondary education initiation, particularly for females. Targeting mediators of the sexual debut-education relationship, such as early childbearing, could lead to effective interventions.

Perspectives on Sexual and Reproductive Health, 2008, 40(3):152-161, doi: 10.1363/4015208
Current U.S. reproductive health policies promote abstinence from sexual activity during the adolescent years, asserting that adolescent sexual activity causes physical and psychological harm. ${ }^{1}$ Research on adolescent sexual activity has found that compared with abstainers, sexually active adolescents are more likely to use substances, have lower academic achievement and aspirations, and experience poorer mental health. ${ }^{2-4}$ Unplanned pregnancy and STDs are also risks of adolescent sex.

Most studies on adolescent sex have examined the associations between sexual debut timing and reproductive and mental health outcomes. However, sexual debut timing has also been related to educational outcomes. In one longitudinal study, Billy et al. found that sexual debut was associated with a decrease in educational aspirations for white adolescent females and a decrease in educational performance for white adolescent males, although it was unassociated with either outcome for black adolescents. ${ }^{3}$ In another longitudinal study, Schvaneveldt et al. found that initiation of sexual intercourse was related to a decrease in self-rated academic performance and educational aspirations for both males and females; racial differences were not examined. ${ }^{5}$ More recently, Sabia found that adolescent sexual initiation was associated with a decrease in educational aspirations over one year, even after unobserved heterogeneity was controlled for; however, the association was limited to females who debuted before age $16 .^{6}$ The prevalence of sexual debut during adolescence is high: According to nationally representative surveys conducted in $2001,61 \%$ of 12 th graders and almost $90 \%$ of young adults aged 18-27 report ever having had sexual intercourse. ${ }^{7,8}$ If the ramifications of adolescent sexual debut are accurately stated, one might expect a cascade of negative consequences into young adulthood.

A number of developmental theories shed light on the findings of studies on adolescent sexual activity. For example, according to the stage termination hypothesis, early occurrence of developmental transitions may be problematic because individuals may lack the necessary skills to navigate transitions successfully. ${ }^{9}$ In the case of sexual activity, individuals who initiate early may not have the capacity for anticipating, and therefore adequately preparing themselves for, potential consequences. Support for this hypothesis can be found in the fact that early sexual debut is associated with lower rates of condom use and higher rates of unintended pregnancy and STD infection than later debut. ${ }^{10-12}$ Further, adolescents with a short dating history may not have the emotional skills to cope with romantic relationship breakup, perhaps especially after sexual initiation. One study, for example, found that associations between sexual debut and 
subsequent depressive symptoms were limited to female adolescents who debuted prior to age 16 and whose relationships had ended. ${ }^{13}$

Another theoretical perspective relevant to studying the effects of adolescent sexual debut is problem behavior theory and the maturational deviance hypothesis. ${ }^{14,15}$ This perspective postulates that early occurrence of a developmental transition can evoke negative reactions from authority figures or conventional peers because it violates socially defined norms. Further, early initiation of transitions can lead to greater affiliation with deviant peers. ${ }^{14}$ Support for this perspective can be found in research that relates adolescent sexual debut to an increase in problem-focused interactions with parents, a decreased sense of belonging at school and decreased participation in religious activities. ${ }^{16,17}$ According to this research, even when sexual activity ceases, relationships with parents, school and religious institutions may not improve, suggesting that in U.S. culture, "sexually active adolescent" is an irreversible stigmatizing label. ${ }^{17}$

Yet another possible explanation for observed associations between sexual debut and educational outcomes is that adolescents who are relatively unlikely to succeed academically are the most likely to have had an early sexual debut. A study by Harris, Duncan and Boisjoly, for example, found that for adolescent males, having high expectations for graduating from college was negatively associated with sexual initiation in a one-year follow-up. ${ }^{18}$ Similarly, Schvaneveldt et al. found that educational goals, interest in school and academic achievement were positively associated with age at sexual debut. ${ }^{5}$ Many background factors that are related to early age at sexual debut are also related to poor educational outcomes, including black race, low family socioeconomic status, low neighborhood socioeconomic status, low cognitive ability, adolescent problem behavior and childhood maltreatment. ${ }^{19-24}$ Although some studies have controlled for some of these possible confounders, none have controlled for all.

Even if we accept the connections between adolescent sexual debut and a decline in educational aspirations and performance during adolescence, how timing of sexual debut relates to longer term outcomes is unclear. Adult educational attainment has its foundations in adolescent high school performance and requires dedication to academic progress. However, differences in educational aspirations and achievement associated with sexual initiation may lessen with time. Normative developmental transitions are often stressful, especially if several occur at about the same time. ${ }^{25}$ However, most young people eventually adapt to new developmental stages and resume normative functioning. ${ }^{26}$ Given that sexual initiation has become statistically normative during adolescence, the educational effects observed in other studies across a relatively brief period may be transitory.

Studies examining the connections between sexual debut timing and adult outcomes have yielded mixed results. For example, Kaestle et al., using data from the National Longitudinal Study of Adolescent Health (Add Health), found that the association between age at sexual debut and STD infection risk decreased with age; ${ }^{27}$ however, Magnusson and Trost, using data from a cohort of Swedish women, found lasting associations between early debut and contraceptive use and menstrual symptoms into middle adulthood. ${ }^{28}$ In other studies, an association between early sexual debut and delinquency outcomes, ${ }^{29}$ but not depressive symptoms, ${ }^{30}$ persisted into early adulthood.

Finally, although studies to date have found a relationship between sexual debut and adolescent educational performance and aspirations among some groups of adolescents, whether these associations differ by relative timing of debut or persist into later life is unknown. One study of educational attainment, using nationally representative data from the National Education Longitudinal Survey, found that youth who delay enrolling in postsecondary education as little as seven months after high school graduation have a reduced likelihood of completing a bachelor's degree, even after prior academic achievement and socioeconomic status are controlled for. ${ }^{20}$ Thus, examining whether sexual debut timing is related to early adult postsecondary initiation is an important next step in assessing the postadolescent implications of adolescent sexual debut.

Building on past research findings, we addressed three research questions in the present study: First, is adolescent sexual debut associated with educational progress (defined as initiation of postsecondary education) in early adulthood? Given past findings of negative associations between sexual debut and adolescent educational aspirations and performance, ${ }^{3,5,6}$ we expect sexual debut during adolescence to be negatively associated with educational progress in early adulthood. Next, does the association between adolescent sexual debut and educational progress vary by relative timing of debut during adolescence? We expect early, but not typical, debut to demonstrate this association. Finally, is the relationship between sexual debut timing and early adult educational progress consistent across gender and race or ethnicity? Because past studies find both gender and racial or ethnic differences in effects of the timing of debut on educational outcomes during adolescence, ${ }^{3,6}$ we expect stronger negative associations between sexual debut timing and educational attainment for females than for males, and for white and Hispanic adolescents than for blacks.

\section{METHODS}

Data

We used data from Waves 1 and 3 of the Add Health contractual data set to address these questions. ${ }^{31}$ Add Health is a prospective cohort study of a nationally representative sample of young people enrolled in grades 7-12 in the 1994-1995 school year (Wave 1). ${ }^{32}$ Early adult follow-up interviews were conducted in 2001 
TABLE 1. Selected characteristics of National Longitudinal Study of Adolescent Health respondents who had not experienced sexual debut at baseline, by gender

\begin{tabular}{ll} 
Characteristic & \\
\hline Female & \\
Race/ethnicity & \\
White & \\
Black & 75 \\
Hispanic & 1 \\
Other & 1 \\
Grade level & \\
7 & \\
8 & 38 \\
9 & \\
$\geq 10$ & 32 \\
Con &
\end{tabular}

\begin{tabular}{lll}
$\begin{array}{l}\text { All } \\
(\mathrm{N}=3,965)\end{array}$ & $\begin{array}{l}\text { Females } \\
(\mathrm{N}=2,264)\end{array}$ & $\begin{array}{l}\text { Males } \\
(\mathrm{N}=1,701)\end{array}$ \\
\hline 53 & na & na
\end{tabular}

$75 \quad 74$

$10-12$

$10-10$

5

4

76

8

10

38
32
24
6

Cognitive ability $\dagger$

39

30

24

7

38

34

24

4

<average

Average

>average

66

Live with two biologic parents

Highest parent education

$<$ high school/GED

High school/GED

Some postsecondary

$\geq$ bachelor's degree

24

66

11
67

67
22

22

9

65

26

66

$\%$ of neighborhood population with <high school diploma

$0-18$

$19-27$

$28-37$

$\geq 38$

$\%$ of neighborhood population below poverty level

$0-5$

6-10

$11-20$

$\geq 21$

Ever held back a grade

Mean grades (range, 1-4)

Expectation of going to college

Low

Moderate

High

Desire to go to college

Low

Moderate

High

Smoked cigarettes in past $\mathbf{3 0}$ days

Used marijuana in past 30 days

Childhood physical neglect

Childhood sexual abuse

Sexual debut timing $\neq$

Early

Typical

Late

Initiated postsecondary education

†Based on Add Health Picture Vocabulary Test score. $\neq$ Debut was considered early if it occurred before age 16; typical, at ages 16-18; and late, after age 18. Notes: na=not applicable. Unless otherwise noted, values shown are percentages. All variables were measured at Wave 1 (1994-1995), except childhood maltreatment, sexual debut timing and postsecondary education initiation, which were measured at Wave 3 (2001).

(Wave 3). Add Health used a multistage probability clustered sampling design to obtain its original sample. In the first stage, a stratified, random sample of all public and private high schools in the United States was selected. A feeder school was also recruited from each participating community. In-school surveys were attempted with all students attending participating schools; a total of 90,118 were completed. In the second Wave 1 sampling stage, a sample of adolescents, consisting of a random core sample plus selected special oversamples, was drawn for in-depth in-home interviews; a total of 20,745 interviews were conducted at this stage. At Wave 3 , all respondents to the Wave 1 in-home interview were eligible for reinterview; 15,170 completed interviews. In all, 14,322 respondents participated in both the Wave 1 and the Wave 3 interviews and had valid sampling weights. Wave 3 respondents are representative of the same population as the original Wave 1 sample when final sampling weights are utilized. ${ }^{33}$

Data at both waves were collected via in-home computer-administered interviews; audio computerassisted self-interviewing was used for sensitive subjects (e.g., sexual activity and drug use) at Wave 1 . We used 1990 census data linked to respondents' Wave 1 residential addresses to capture residential neighborhood characteristics.

\section{Measures}

-Outcome. Data from questions asking respondents' highest grade level completed, degrees received and in-school status at Wave 3 were combined to form the two-category outcome variable: respondent did not yet initiate postsecondary education (coded as 0 ) and respondent did initiate postsecondary education (coded as 1). Those who had both completed a high school degree or GED and enrolled in any subsequent two- or four-year program were considered to have initiated postsecondary education.

-Predictor. The main predictor variable, sexual debut timing, was derived from respondents' Wave 3 report of age (in years) at first sexual intercourse (defined as vaginal intercourse). This variable was transformed into an ordinal indicator of timing, given the nonnormality of the distribution and right censorship of the data (not all respondents had debuted by Wave 3). The specification was based on design-corrected and weighted approximate tertiles of reported debut age among the 14,322 respondents who participated in both Waves 1 and 3 . The "early" debut category consisted of those aged 1015 at debut; the "typical" category, those aged 16-18; and the "late" category, those older than 18 and those who had not experienced sexual intercourse by Wave 3 . Use of the Wave 3 report was necessary because of the sample inclusion criterion that respondents had not had sexual intercourse at Wave 1. Although reported age at sexual debut varies somewhat as people age, this variability in Add Health has little substantive effect on estimated distributions of debut timing or on covariates of age at sexual debut. ${ }^{34}$ Further, as self-reported honesty in answering sexual behavior questions increases with age, use of the Wave 3 report may be the 
most valid. ${ }^{35}$ Use of the Wave 3 report of age at sexual debut also has precedent in other Add Health analyses. $^{27}$

-Covariates. In multivariable analyses, we controlled for characteristics the literature or preliminary bivariate analyses supported as potential risk or protective factors for both sexual debut timing and educational attainment. Demographic and background variables included gender, race or ethnicity (categorized as non-Hispanic white, non-Hispanic black, Hispanic and non-Hispanic other), grade level at Wave 1 and cognitive ability at Wave 1 (based on the Add Health Picture Vocabulary Test score and categorized as below average, average or above average).

Family characteristics were measured by adolescents' Wave 1 report. Living arrangement was based on the adolescent's reported household roster and was dichotomized to indicate whether the respondent lived with both biologic parents. Parent education, denoting the highest level attained by either residential parent, was categorized as less than high school diploma, high school diploma or GED, some postsecondary, or bachelor's degree or higher.

Two variables characterizing adolescents' neighborhood, based on respondents' Wave 1 residential census tract, were also included. Neighborhood education was measured as the percentage of the census tract population older than 25 who had less than a high school education. Neighborhood poverty was based on the percentage of the census tract population living below the federal poverty line. Both neighborhood variables were categorized into quartiles, and entered into models as individual-level covariates. Multilevel analyses were not conducted because nearly $50 \%$ of the included census tracts contained only one respondent.

Adolescent academic achievement was characterized using two Wave 1 variables. First, the adolescent's report of ever being held back a grade was included as a dichotomous indicator (yes was coded as 1 ; no, 0). Second, a grade point average proxy was based on the respondent's reported past semester grades in English, math, history or social studies, and science (D or lower was coded as 1, C as 2, B as 3 and A as 4). The mean of all nonmissing items was calculated.

Adolescent educational expectancies were also captured using two Wave 1 variables: how much the respondent expected to attend college and how much the respondent wanted to attend college. Both variables were originally measured on a scale from 1 (low) to 5 (high). In preliminary bivariate analyses, response levels 1-3 did not significantly differ in their association with either debut timing or postsecondary education initiation. Therefore, we categorized expectancies as high (score of 5), moderate (4) or low (1-3).

Finally, dichotomous controls for respondents' risk and negative experiences were included (for all measures,
TABLE 2. Selected characteristics of respondents who had not experienced sexual debut at baseline, by timing of debut and initiation of postsecondary education

Characteristic

\begin{tabular}{lllc|cc} 
& \multicolumn{3}{l|}{ Sexual debut } & \multicolumn{2}{l}{$\begin{array}{l}\text { Postsecondary } \\
\text { education }\end{array}$} \\
\cline { 2 - 6 } & Early & Typical & Late & No & Yes \\
\hline Female & 58 & 52 & $50^{*}$ & 47 & $55^{* * *}$ \\
Race/ethnicity & & & & & \\
White & 75 & 74 & $76^{* *}$ & 70 & $77^{* *}$ \\
Black & 13 & 11 & 7 & 12 & 9 \\
Hispanic & 10 & 10 & 11 & 14 & 9 \\
Other & 2 & 5 & 6 & 4 & 5
\end{tabular}

Other

Grade level

7

8

9

$\geq 10$

Cognitive ability

$<$ average

Average

>average

Live with two biologic parents

Highest parent education

$<$ high school/GED

High school/GED

Some postsecondary

$\geq$ bachelor's degree

$\%$ of neighborhood population with <high school diploma

$\begin{array}{llll}0-18 & 29 & 28 & 38^{*}\end{array}$

$19-27$

$28-37$

$33 \quad 31$

$\geq 38$

$21 \quad 24$

$\%$ of neighborhood population below poverty level

$0-5$

6-10

$11-20$

$\geq 21$

Ever held back a grade

Mean grades (range, 1-4)

$24 \quad 24$

$\begin{array}{ll}24 & 24 \\ 28 & 29\end{array}$

$26 \quad 26$

$21 \quad 21$

Mean grades (range, 1-4)

$\begin{array}{lll}10 & 12 \quad 11\end{array}$

Expectation of going to college

Low

Moderate

High

Desire to go to college
Low
Moderate
High

Smoked cigarettes in past 30 days

Used marijuana in past 30 days

Childhood physical neglect

Childhood sexual abuse

Initiated postsecondary education

2.8
20
28
53

${ }^{*} p<.05 .{ }^{* *} p<.01 .{ }^{* *} p<.001 .+p<.10 . \neq$ Based on Add Health Picture Vocabulary Test score. Notes: na=not applicable. Unless otherwise noted, values shown are percentages. All variables were measured at Wave 1 (19941995), except childhood maltreatment, sexual debut timing and postsecondary education initiation, which were measured at Wave 3 (2001). Differences among distributions were determined using two-tailed Pearson chi-square tests for categorical variables, or two-tailed t tests or analysis of variance for continuous variables.

no was coded as 0 and yes as 1). Two indicators of adolescent substance use were constructed, reflecting any use of cigarettes or marijuana in the 30 days before the Wave 1 interview. Further, two indicators of childhood maltreatment by a parent or caretaker prior to the sixth 
TABLE 3. Relative risk ratios (and $95 \%$ confidence intervals) from Poisson regression models examining associations between selected characteristics and females' initiation of postsecondary education by early adulthood

\begin{tabular}{|c|c|c|c|}
\hline Characteristic & Model 1 & Model 2 & Model 3 \\
\hline \multicolumn{4}{|l|}{ Sexual debut timing } \\
\hline Early & $0.61(0.52-0.72)^{* * *}$ & $0.78(0.68-0.89)^{* * *}$ & $0.84(0.74-0.96)^{*}$ \\
\hline Typical & $0.77(0.72-0.83)^{* * *}$ & $0.87(0.82-0.92)^{* * *}$ & $0.91(0.86-0.96)^{* *}$ \\
\hline Late (ref) & 1.00 & 1.00 & 1.00 \\
\hline \multicolumn{4}{|l|}{ Race/ethnicity } \\
\hline White (ref) & na & 1.00 & 1.00 \\
\hline Black & na & $1.20(1.07-1.35)^{* *}$ & $1.23(1.11-1.36)^{* * *}$ \\
\hline Hispanic & na & $1.03(0.88-1.21)$ & $1.08(0.93-1.26)$ \\
\hline Other & na & $1.09(0.96-1.24)$ & $1.08(0.95-1.23)$ \\
\hline Grade level & na & $1.02(0.98-1.05)$ & $1.03(1.00-1.07)^{*}$ \\
\hline \multicolumn{4}{|l|}{ Cognitive ability } \\
\hline$<$ average & na & $0.82(0.67-1.00)$ & $0.81(0.66-1.00) \dagger$ \\
\hline Average (ref) & na & 1.00 & 1.00 \\
\hline >average & na & $1.01(0.95-1.08)$ & $1.00(0.95-1.07)$ \\
\hline Live with two biologic parents & na & $1.10(1.03-1.18)^{* *}$ & $1.08(1.01-1.16)^{*}$ \\
\hline \multicolumn{4}{|l|}{ Highest parent education } \\
\hline$<$ high school/GED & na & $0.61(0.46-0.81)^{* *}$ & $0.63(0.47-0.84)^{* *}$ \\
\hline High school/GED (ref) & na & 1.00 & 1.00 \\
\hline Some postsecondary & na & $1.15(1.04-1.27)^{*}$ & $1.14(1.04-1.25)^{*}$ \\
\hline$\geq$ bachelor's degree & na & $1.21(1.10-1.34)^{* * *}$ & $1.18(1.08-1.29)^{* *}$ \\
\hline $\begin{array}{l}\% \text { of neighborhood population } \\
\text { with <high school diploma }\end{array}$ & na & $1.02(0.98-1.07)$ & $1.02(0.98-1.07)$ \\
\hline $\begin{array}{l}\% \text { of neighborhood population } \\
\text { below poverty level }\end{array}$ & na & $0.97(0.93-1.01)$ & $0.99(0.95-1.03)$ \\
\hline Ever held back a grade & na & $0.78(0.66-0.92)^{* *}$ & $0.78(0.66-0.93)^{* *}$ \\
\hline Mean grades & na & $1.27(1.18-1.36)^{* * *}$ & $1.25(1.16-1.33)^{* * *}$ \\
\hline \multicolumn{4}{|l|}{ Expectation of going to college } \\
\hline Low & na & $0.64(0.51-0.81)^{* * *}$ & $0.66(0.52-0.83)^{* * * *}$ \\
\hline Moderate & na & $0.92(0.84-1.02)$ & $0.92(0.83-1.01)$ \\
\hline High (ref) & na & 1.00 & 1.00 \\
\hline \multicolumn{4}{|l|}{ Desire to go to college } \\
\hline Low & na & $0.84(0.67-1.06)$ & $0.86(0.69-1.07)$ \\
\hline Moderate & na & $0.97(0.85-1.11)$ & $0.97(0.85-1.09)$ \\
\hline High (ref) & na & 1.00 & 1.00 \\
\hline $\begin{array}{l}\text { Smoked cigarettes } \\
\text { in past } 30 \text { days }\end{array}$ & na & $0.91(0.80-1.02)$ & $0.92(0.82-1.03)$ \\
\hline Used marijuana in past 30 days & na & $1.06(0.85-1.32)$ & $1.03(0.83-1.26)$ \\
\hline Childhood physical neglect & na & $0.79(0.65-0.96)^{*}$ & $0.82(0.68-1.00)^{*}$ \\
\hline Childhood sexual abuse & na & $1.06(0.87-1.29)$ & $1.01(0.83-1.23)$ \\
\hline Childbearing & na & na & $0.52(0.41-0.65)^{* * *}$ \\
\hline$F_{d f}$ & $36.58_{2,127^{* * *}}$ & $13.34_{24,104^{* * *}}$ & $13.26_{25,103^{* * *}}$ \\
\hline
\end{tabular}

${ }^{*} p<.05 .{ }^{* *} p<.01 .{ }^{* * *} p<.001 .+p<.10$. $¥$ Based on Add Health Picture Vocabulary Test score. Notes: ref=reference group. na=not applicable. All variables were measured at Wave 1 (1994-1995), except childhood maltreatment, sexual debut timing, postsecondary education initiation and childbearing, which were measured at Wave 3 (2001). All $p$ values are Bonferroni-adjusted. Characteristics for which no reference group is shown were measured as a continuous variable (mean grades), an ordered categorical variable (grade level, percentage of neighborhood population with less than a high school diploma and below poverty level) or a dichotomous variable where "no" is the reference category (all others).

grade were based on Wave 3 retrospective report: physical neglect (signifying that basic needs, such as food or clothing were not taken care of) and sexual abuse (respondents were asked if they had been touched or been forced to touch a parent or caretaker in a sexual manner or if their parent or caretaker had forced them to have sexual relations).

\section{Analyses}

Our analyses are limited to respondents who participated in Waves 1 and 3, and had longitudinal sample weights available; had not experienced sexual intercourse and were younger than 16 at Wave 1; and had complete data on debut timing, postsecondary initiation and all covariates of interest. Our final sample consisted of 3,965 respondents. Limitation to those who had not yet experienced sexual debut by Wave 1 was necessary to control for predebut characteristics, and to adequately address the temporal ordering of educational aspirations and sexual debut. Age limitations were necessary to ensure that all included participants had the opportunity to be part of any of the three debut timing groups (early, typical, late).

All analyses were conducted in Stata version 9, with variance corrections for clustering at the school level and weighted to yield nationally representative estimates. Weighted proportions were run to describe the sample's personal, family and neighborhood characteristics. Chisquare analyses and analyses of variance were performed to test associations between control variables and both timing of sexual debut and initiation of postsecondary education. Finally, the relevance of sexual debut timing for postsecondary initiation was tested with two multivariable Poisson regression models, run separately by gender.* The first model was fit to estimate the crude relationship between sexual debut timing and postsecondary education initiation. The second included all control variables, the main independent variable, and the interaction of race and debut timing. Our hypotheses testing was conducted with alpha set at .05 , except for interaction terms, where it was set at .15 .

In preliminary analyses, interactions between debut timing and race or ethnicity were insignificant for both males $(p=0.9)$ and females $(p=0.2)$, indicating no significant racial or ethnic differences in the relationship between sexual debut timing and early adult postsecondary education initiation. Therefore, multivariable models were subsequently fit without these interaction terms. Risk ratios for postsecondary education initiation were calculated by exponentiating the estimated regression coefficients.

\section{RESULTS}

Slightly more than half of the respondents were female (Table 1, page 154 ). The majority (75\%) were white, $10 \%$ were black, 10\% were Hispanic and 5\% were of some other

* In circumstances where an outcome is common (i.e., prevalence is greater than $10 \%$ ), odds ratios generated by a logistic regression model overestimate the relative risk (source: McNutt LA et al., Estimating the relative risk in cohort studies and clinical trials of common outcomes, American Journal of Epidemiology, 2003, 157(10):940-943). To directly estimate relative risk, log binomial models are recommended; however, such models often do not converge. Alternately, in closed cohort studies, Poisson regression models can be used to estimate relative risks, with a time-at-risk value specified as 1 for each observation. 
race or ethnicity. Sixty-six percent of participants lived with both biologic parents, and $61 \%$ had a parent with at least some postsecondary education. More than two-thirds reported sexual debut during adolescence- $15 \%$ prior to age 16 and 53\% between ages 16 and 18. At Wave 1, the majority of respondents expected to and wanted to go to college (59\% and 79\%, respectively). By early adulthood, $65 \%$ of respondents had initiated postsecondary education.

In crude bivariate analyses, sexual debut timing was strongly associated with early adult postsecondary initiation (Table 2, page 155). Forty-nine percent of those who had had an early debut had initiated postsecondary education by Wave 3, compared with $63 \%$ of those who had had a typical debut and $78 \%$ of those who had debuted late. Both debut timing and postsecondary educational advancement were associated with many risk and protective factors: In general, even prior to sexual debut, those who debuted late had more protective and fewer risk factors than those who reported early or typical debut. For example, $73 \%$ of those who had debuted late lived with both biologic parents in adolescence, compared with $65 \%$ of those who had had a typical debut and $53 \%$ of those who had had an early debut. Further, although $63 \%$ of those who had had a late debut had high expectations for attending college, only $53 \%$ of those who had had an early debut had similarly high expectations. Also, reports of smoking cigarettes were more than three times as common among those who had debuted early as among those who had debuted late.

Many of the risk and protective factors that were associated with timing of sexual debut were also significantly associated with postsecondary education initiation in early adulthood. For example, female gender, white race, cognitive ability, living with both biologic parents, mean grades, neighborhood education and desire to go to college were all positively associated with both postsecondary education initiation and delayed sexual debut. Further, cigarette and marijuana use and childhood maltreatment were negatively associated with both postsecondary education initiation and timing of sexual debut.

For females, the association between sexual debut timing and educational progress in early adulthood greatly decreased after the addition of control variables to the model (Table 3). However, even after adjustment, both early and typical debut timing remained moderately negatively associated with postsecondary education initiation in early adulthood. In our crude model, females who had had an early debut and those who had had a typical debut were less likely than females who had debuted late to have initiated postsecondary education by early adulthood (relative risk ratios, 0.6 and 0.8 , respectively). However, after adjustment for differences in background characteristics and predebut academic performance and aspirations, the relative disadvantage of both early and typical initiators was attenuated ( 0.8 and 0.9 , respectively). In adjusted models, many of the risk and protective factors identified in bivariate analyses
TABLE 4. Relative risk ratios (and 95\% confidence intervals) from Poisson regression models examining associations between selected characteristics and males' initiation of postsecondary education by early adulthood

\begin{tabular}{|c|c|c|c|}
\hline Characteristic & Model 1 & Model 2 & Model 3 \\
\hline \multicolumn{4}{|l|}{ Sexual debut timing } \\
\hline Early & $0.65(0.51-0.83)^{* *}$ & $0.80(0.65-0.97) \dagger$ & $0.84(0.69-1.03)$ \\
\hline Typical & $0.84(0.76-0.94)^{* *}$ & $0.94(0.86-1.02)$ & $0.97(0.90-1.05)$ \\
\hline Late (ref) & 1.00 & 1.00 & 1.00 \\
\hline \multicolumn{4}{|l|}{ Race/ethnicity } \\
\hline White (ref) & na & 1.00 & 1.00 \\
\hline Black & na & $1.12(0.94-1.33)$ & $1.14(0.96-1.36)$ \\
\hline Hispanic & na & $1.15(0.97-1.36)$ & $1.14(0.98-1.33)$ \\
\hline Other & na & $0.99(0.84-1.17)$ & $0.98(0.84-1.16)$ \\
\hline Grade level & na & $1.05(1.00-1.10) \dagger$ & $1.05(1.00-1.10)^{*}$ \\
\hline \multicolumn{4}{|l|}{ Cognitive ability $\ddagger$} \\
\hline <average & na & $1.04(0.85-1.27)$ & $1.03(0.85-1.26)$ \\
\hline Average (ref) & na & 1.00 & 1.00 \\
\hline >average & na & $1.06(0.98-1.16)$ & $1.05(0.97-1.14)$ \\
\hline Live with two biologic parents & na & $1.07(0.97-1.19)$ & $1.07(0.96-1.18)$ \\
\hline \multicolumn{4}{|l|}{ Highest parent education } \\
\hline$<$ high school/GED & na & $0.72(0.52-1.00)$ & $0.76(0.55-1.04)$ \\
\hline High school/GED (ref) & na & 1.00 & 1.00 \\
\hline Some postsecondary & na & $1.23(1.05-1.44)^{*}$ & $1.20(1.04-1.39)^{*}$ \\
\hline zbachelor's degree & na & $1.32(1.14-1.54)^{* *}$ & $1.29(1.12-1.48)^{* *}$ \\
\hline $\begin{array}{l}\% \text { of neighborhood population } \\
\text { with <high school diploma }\end{array}$ & na & $0.97(0.91-1.03)$ & $0.97(0.91-1.03)$ \\
\hline$\%$ of neighborhood population & & & \\
\hline below poverty level & na & $0.97(0.92-1.03)$ & $0.97(0.92-1.03)$ \\
\hline Ever held back a grade & na & $0.87(0.71-1.06)$ & $0.91(0.75-1.11)$ \\
\hline Mean grades & na & $1.36(1.24-1.49)^{* * *}$ & $1.34(1.23-1.46)^{* * *}$ \\
\hline \multicolumn{4}{|l|}{ Expectation of going to college } \\
\hline Low & na & $0.44(0.30-0.65)^{* * *}$ & $0.44(0.30-0.64)^{* * *}$ \\
\hline Moderate & na & $0.88(0.78-1.01)$ & $0.90(0.78-1.02)$ \\
\hline High (ref) & na & 1.00 & 1.00 \\
\hline \multicolumn{4}{|l|}{ Desire to go to college } \\
\hline Low & na & $0.77(0.61-0.96)^{*}$ & $0.78(0.62-0.97) \dagger$ \\
\hline Moderate & na & $0.96(0.86-1.06)$ & $0.95(0.86-1.05)$ \\
\hline High (ref) & na & 1.00 & 1.00 \\
\hline $\begin{array}{l}\text { Smoked cigarettes } \\
\text { in past } 30 \text { days }\end{array}$ & na & $1.03(0.86-1.24)$ & $1.04(0.87-1.23)$ \\
\hline Used marijuana in past 30 days & na & $0.93(0.68-1.25)$ & $0.91(0.67-1.24)$ \\
\hline Childhood physical neglect & na & $0.96(0.80-1.16)$ & $0.95(0.79-1.15)$ \\
\hline Childhood sexual abuse & na & $0.85(0.62-1.17)$ & $0.82(0.60-1.11)$ \\
\hline Childbearing & na & na & $0.40(0.27-0.61)^{* * *}$ \\
\hline$F_{d f}$ & $8.46_{2,127^{* * *}}$ & $14.93_{24,104^{* * *}}$ & $15.34_{25,103^{* *}}$ \\
\hline
\end{tabular}

${ }^{*} \mathrm{p}<.05 .{ }^{* *} \mathrm{p}<.01 .{ }^{* * *} \mathrm{p}<.001 .+\mathrm{p}<.10 .$. Based on Add Health Picture Vocabulary Test score. Notes: ref=reference group. na=not applicable. All variables were measured at Wave 1 (1994-1995), except childhood maltreatment, sexual debut timing, postsecondary education initiation and childbearing, which were measured at Wave 3 (2001). All p values are Bonferroni-adjusted. Characteristics for which no reference group is shown were measured as a continuous variable (mean grades), an ordered categorical variable (grade level, percentage of neighborhood population with less than a high school diploma and below poverty level) or a dichotomous variable where "no" is the reference category (all others).

remained significantly associated with postsecondary education initiation, including race or ethnicity, living with both biologic parents, parental education, ever being held back a grade, mean grades, expectation of going to college and childhood physical neglect.

As with females, both early and typical debut were significantly negatively related to early adult 
postsecondary education initiation in crude models among males (Table 4). Although males who had debuted early were estimated to be 0.7 times as likely as those who had debuted late to have initiated postsecondary education by early adulthood in the crude model, this relative disadvantage became much smaller and was only marginally significant in the adjusted model (relative risk ratio, 0.8). Further, the discrepancy in likelihood of early adult postsecondary education initiation between males reporting a typical debut and those reporting a late debut found in the crude model (0.8) became insignificant after adjustment for predebut characteristics (0.9). The addition of parent education, predebut academic achievement (i.e., mean grades), as well as predebut expectation and desire to attend college, seems particularly important in explaining this difference.

Although the primary aim of this analysis was to Generally, examine whether associations between adolescent sexrespondents reporting early or typical debut timing had more

educational risk factors and fewer educational protective factors than those who debuted late. ual debut and educational attainment held after potential confounding factors were adjusted for, findings of negative associations leave unanswered the question of how sexual debut timing may exert influence. One likely explanatory factor is childbearing, given the links between early sexual activity and pregnancy risk, as well as those between early childbearing and educational progress in early adulthood. ${ }^{36,37}$ In this sample, $20 \%$ of those reporting early, $13 \%$ of those reporting typical and $2 \%$ of those reporting late debut had had children by Wave 3 (not shown). In an additional model run for each gender, we examined the mediating effect of childbearing by adding to the fully adjusted model a variable indicating respondents' having had at least one child by Wave 3. Childbearing was strongly negatively associated with early adult postsecondary initiation for both females (relative risk ratio, 0.5) and males (0.4). For females, although educational progress differences between late and other debut timing groups remained statistically significant, they became smaller (from 0.78 to 0.84 for early debut and from 0.87 to 0.91 for typical). For males, addition of childbearing to the model rendered the marginally significant association between debut timing and postsecondary education insignificant.

\section{DISCUSSION}

In the present study, we found that relative sexual debut timing was associated with a range of risk and protective factors that were also correlated with early adult educational progress. Generally, respondents reporting early or typical debut timing had more educational risk factors and fewer educational protective factors than those who debuted late. Early sexual debut had a moderate negative association with early adult educational progress across race or ethnicity and gender. After demographic, risk and protective factors were controlled for, associations were greatly attenuated. This suggests that part of the crude estimated association between sexual debut timing and educational progress in early adulthood is attributable to background and experiential characteristics that exist prior to sexual debut. However, modest associations were still observed after these variables were controlled for, supporting a possible independent relationship between debut timing and early adult educational progress. This finding extends past research that has linked adolescent sexual debut with short-term negative changes in educational performance and goals, and suggests that these short-term associations may have modest but lasting implications. $^{3,5,6,17}$

The negative association with educational progress was smaller for typical than for early debut; further, after adjustment for predebut characteristics and experiences, this association was significant for females only. Although some past research has found adolescent sexual debut negatively related to short-term educational changes for both females and males, ${ }^{3,5}$ gender differences in other consequences of sexual debut are apparent in the literature. We noted earlier that early sexual transition may prompt a series of negative and perhaps irreversible consequences, including worsened relations with parents and conventional institutions, and consequential association with unconventional peers. This process may be heightened for females. Qualitative studies have found that females in the United States are subject to more social sanctions after sexual debut than males, including pejorative labeling by peers and problem-focused parental interactions. ${ }^{38,39}$ Such negative environmental feedback has likewise been connected to postdebut depressive symptom changes, ${ }^{17}$ which may be greater for females than for males. ${ }^{13,40}$ It is possible that the higher likelihood of early childbearing and subsequent lower likelihood of postsecondary education initiation for females with early or typical versus late debut are related to depressive symptomatology, which is a risk factor for both early pregnancy and declining academic performance. ${ }^{41,42}$ Future research with more frequent short-term follow-up interviews is needed to better explore these mechanisms.

Another plausible explanation for the observed associations between early and typical debut timing and later postsecondary education initiation is that they reflect residual unmeasured heterogeneity. As demonstrated in bivariate analyses, adolescents who experience early sexual debut have many socioeconomic and other characteristics that place them at risk for both early debut and later adverse socioeconomic outcomes. Unless this full range of factors can be adequately measured and analyzed, results may reflect the effect not only of sexual debut, but also of unmeasured factors. For example, when educational differences between siblings who have had an adolescent birth and those who have not are examined, the effect estimates of adolescent childbearing are greatly reduced (though still significant) compared with estimates from analyses using unmatched samples. ${ }^{43,44}$ Although we tried to include many of the salient social, demographic, experiential and adolescent characteristics in our models, our variables may not fully capture the 
complex processes that affect selection into both early debut and later educational progress. Therefore, these modest associations, like findings in the teenage childbearing literature, may overestimate the relationship between adolescent sexual debut and postsecondary education initiation. Future research using matched twin or sibling data may help shed light on this question.

In contrast to Billy et al., ${ }^{3}$ we found that the relationship between sexual debut and educational progress was similar across racial and ethnic groups. Our divergent findings may have several explanations. First, Billy et al. examined the effects of any sexual transition on educational progress, while we examined the relative timing of that transition. Second, Billy et al. used a sample of Florida high school students in 1980-1982, while we employed data from a nationally representative survey of students enrolled in junior high or high school in 1994-1995. The smaller sample size in the earlier study may have affected the authors' ability to detect significant differences in educational outcomes by sexual debut status for the different racial and ethnic subgroups. In a number of cases, their estimated regression coefficients were similar across racial and ethnic groups, although statistical significance was found only in some subgroups. Because of the differences in research questions, sample composition and sizes, historical period and follow-up times, it is possible that both studies have valid findings. Replications of this analysis using different study samples are warranted.

Our final major finding is that estimated associations between adolescent sexual debut and later educational progress for females are largely mediated through early childbearing. Although Geronimus found that adolescent childbearing was unrelated to adult educational attainment after unobserved family factors were accounted for, ${ }^{45}$ others have found a small association after such characteristics are accounted for. ${ }^{37}$ Adolescent childbearing, however, is not strictly deterministic of later educational attainment, as such attainment varies by mothers' prepregnancy socioeconomic status and educational aspirations. ${ }^{46}$ A substantial proportion of those who had had an early sexual debut in the present study demonstrate educational progress similar to that of those who debuted later. Future research should explore factors that protect educational attainment among those who have had an early sexual debut.

\section{Limitations}

Our analysis builds upon past research on the effects of adolescent sexual debut on longer term outcomes by differentiating the timing of sexual debut and by using a nationally representative sample. However, a number of study limitations must also be acknowledged. First, although we examined the initiation of postsecondary education over a longer time period than previous studies, whether sexual debut timing relates to total educational attainment at a later point in time is worth exploring in future studies. Analyses using later follow-up data are warranted, especially given past findings of late educational attainment among adolescent parents. ${ }^{46} \mathrm{Sec}-$ ond, we examine only relationships between the timing of first vaginal sexual intercourse and postsecondary education initiation because we do not have data regarding the timing of first oral or anal sexual intercourse. Given documented differential short-term impacts of various sexual activities during adolescence, ${ }^{47}$ our findings may be relevant only to initiation of vaginal sexual intercourse. Finally, despite our use of educational, family, neighborhood and demographic control variables, the observed modest association between sexual debut timing and educational progress may have resulted from residual unmeasured heterogeneity. Replications of our analyses using matched sibling samples or across other U.S. data sets would be helpful in testing the robustness of this association.

\section{Conclusion}

Given that more than 90\% of 18-27-year-olds in the United States in 2001 reported having experienced sexual debut by emerging adulthood, before marriage, ${ }^{8}$ our findings suggest that a policy response that is based solely on postponement of sexual debut until marriage is unlikely to succeed in protecting educational attainment. Targeting mediators of the sexual debut-education relationship seems a more realistic and appropriate response. Previous research suggests that these mediators may include adolescent depressive symptomatology, attachment to school and parents, and access to and education about contraception to prevent early pregnancy. Additionally, our findings of gender differences in the association between debut timing and educational progress, in combination with past qualitative studies' findings of gender differences in postdebut social sanctions, ${ }^{38,39}$ suggest that the cultural interpretation of female adolescents' sexual initiation may also play a role in observed outcomes. Cross-national comparative studies have found that despite similar timing of sexual initiation, adolescents in other developed countries have much lower rates of STDs and pregnancy; ${ }^{48,49}$ therefore, social scripts of adolescent sexuality could also be an important potential intervention target.

\section{REFERENCES}

1. Golden AL, Abstinence and abstinence-only education, Journal of Adolescent Health, 2006, 39(2):151-152.

2. Burge $\mathrm{V}$ et al., Drug use, sexual activity, and suicidal behavior in U.S. high school students, Journal of School Health, 1995, 65(6): 222-227.

3. Billy JO et al., Effects of sexual activity on adolescent social and psychological development, Social Psychology Quarterly, 1988, 51(3): 190-212.

4. Hallfors DD et al., Adolescent depression and suicide risk: association with sex and drug behavior, American Journal of Preventive Medicine, 2004, 27(3):224-231.

5. Schvaneveldt PL et al., Academic goals, achievement, and age at first sexual intercourse: longitudinal, bidirectional influences, Adolescence, 2001, 36(144):767-787. 
6. Sabia JJ, Early adolescent sex and diminished school attachment: selection or spillovers? Southern Economic Journal, 2007, 74(1): 239-268.

7. Brener $\mathrm{N}$ et al., Trends in HIV-related risk behaviors among high school students-United States, 1991-2005, Morbidity and Mortality Weekly Report, 2006, 55(31):851-854.

8. Halpern CT et al., Adolescent predictors of emerging adult sexual patterns, Journal of Adolescent Health, 2006, 39(6):e1-e10.

9. Petersen AC and Taylor B, The biological approach to adolescence: biological change and psychological adaptation, in: Adelson J, ed., Handbook of Adolescent Psychology, New York: Wiley, 1980, pp. 117-155.

10. Upchurch DM et al., Social and behavioral determinants of self-reported STD among adolescents, Perspectives on Sexual and Reproductive Health, 2004, 36(6):276-287.

11. O'Donnell BL, O'Donnell CR and Stueve A, Early sexual initiation and subsequent sex-related risks among urban minority youth: the Reach for Health study, Family Planning Perspectives, 2001, 33(6):268-275.

12. Mosher WD and McNally JW, Contraceptive use at first premarital intercourse: United States, 1965-1988, Family Planning Perspectives, 1991, 23(3):108-116.

13. Meier AM, Adolescent first sex and subsequent mental health, American Journal of Sociology, 2007, 112(6):1811-1847.

14. Jessor R and Jessor SL, Problem Behavior and Psychosocial Development: A Longitudinal Study of Youth, New York: Academic Press, 1977.

15. Alsaker FD, Timing of puberty and reactions to pubertal changes, in: Rutter M, ed., Psychosocial Disturbances in Young People: Challenges for Prevention, Cambridge, UK: Cambridge University Press, 1995, pp. 37-82.

16. Ream GL and Savin-Williams RC, Reciprocal associations between adolescent sexual activity and quality of youth-parent interactions, Journal of Family Psychology, 2005, 19(2): 171-179.

17. Ream GL, Reciprocal effects between the perceived environment and heterosexual intercourse among adolescents, Journal of Youth and Adolescence, 2006, 35(5):771-785.

18. Harris KM, Duncan GJ and Boisjoly J, Evaluating the role of "nothing to lose" attitudes on risky behavior in adolescence, Social Forces, 2002, 80(3):1005-1039.

19. Maruyama G, Disparities in educational opportunities and outcomes: what do we know and what can we do? Journal of Social Issues, 2003, 59(3):653-676.

20. Bozick R and DeLuca S, Better late than never? delayed enrollment in the high school to college transition, Social Forces, 2005, 84(1):531-554.

21. Boyle MH et al., Neighborhood and family influences on educational attainment: results from the Ontario Child Health Study Follow-Up 2001, Child Development, 2007, 78(1):168-189.

22. Heard HE, Fathers, mothers, and family structure: family trajectories, parent gender, and adolescent schooling, Journal of Marriage and Family, 2007, 69(2):435-450.

23. King KM et al., Marker or mediator? the effects of adolescent substance use on young adult educational attainment, Addiction, 2006, 101(12):1730-1740.

24. Shonk SM and Cicchetti D, Maltreatment, competency deficits, and risk for academic and behavioral maladjustment, Developmental Psychology, 2001, 37(1):3-17.

25. Graber JA and Brooks-Gunn J, Transitions and turning points: navigating the passage from childhood through adolescence, Developmental Psychology, 1996, 32(4):768-776.

26. Graber JA, Brooks-Gunn J and Galen BR, Betwixt and between: sexuality in the context of adolescent transitions, in: Jessor R., ed.,
New Perspectives on Adolescent Health Risk Behavior, New York: Cambridge University Press, 1998, pp. 270-316.

27. Kaestle CE et al., Young age at first sexual intercourse and sexually transmitted infections in adolescents and young adults, American Journal of Epidemiology, 2005, 161(8):774-780.

28. Magnusson $C$ and Trost $K$, Girls experiencing sexual intercourse early: could it play a part in reproductive health in middle adulthood? Journal of Psychosomatic Obstetrics and Gynaecology, 2006, 27(4):237-244

29. Armour $S$ and Haynie DL, Adolescent sexual debut and later delinquency, Journal of Youth and Adolescence, 2007, 36(2):141-152.

30. Spriggs A and Halpern CT, Sexual debut timing and depressive symptoms in emerging adulthood, Journal of Youth and Adolescence, 2008 (forthcoming).

31. Udry JR, The National Longitudinal Study of Adolescent Health (Add Health), Waves I \& II, 1994-1996; Wave III, 2001-2002, Chapel Hill, NC: Carolina Population Center, University of North Carolina at Chapel Hill, 2003.

32. Harris KM et al., The National Longitudinal Study of Adolescent Health: research design, 2003, <http://www.cpc.unc.edu/ projects/addhealth/design>, accessed Oct. 23, 2007.

33. Chantala K, Kalsbeek WD and Andraca E, Nonresponse in Wave III of the Add Health Study, Chapel Hill, NC: Carolina Population Center, University of North Carolina at Chapel Hill, 2004.

34. Upchurch DM et al., Inconsistencies in reporting the occurrence and timing of first intercourse among adolescents, Journal of Sex Research, 2002, 39(3):197-206.

35. Siegel DM, Aten MJ and Roghmann KJ, Self-reported honesty among middle and high school students responding to a sexual behavior questionnaire, Journal of Adolescent Health, 1998, 23(1): $20-28$.

36. Kirby D, Antecedents of adolescent initiation of sex, contraceptive use, and pregnancy, American Journal of Health Behavior, 2002, 26(6):473-485.

37. Hoffman SD, Teenage childbearing is not so bad after all... or is it? a review of the new literature, Family Planning Perspectives, 1998, 30(5):236-239.

38. Shoveller JA et al., Socio-cultural influences on young people's sexual development, Social Science \& Medicine, 2004, 59(3): 473-487.

39. Tolman DL, Dilemmas of Desire: Teenage Girls Talk About Sexuality, Cambridge, MA: Harvard University Press, 2002.

40. Waller MW et al., Gender differences in associations between depressive symptoms and patterns of substance use and risky sexual behavior among a nationally representative sample of U.S. adolescents, Archives of Women's Mental Health, 2006, 9(3):139-150.

41. Franko DL et al., Psychosocial and health consequences of adolescent depression in black and white young adult women, Health Psychology, 2005, 24(6):586-593.

42. Quinlivan JA et al., Impact of demographic factors, early family relationships and depressive symptomatology in teenage pregnancy, Australian and New Zealand Journal of Psychiatry, 2004, 38(4): 197-203.

43. Geronimus AT and Korenman S, The socioeconomic consequences of teen childbearing reconsidered, Quarterly Journal of Economics, 1992, 107(4):1187-1214.

44. Hoffman SD, Foster EM and Furstenberg FF, Jr., Reevaluating the costs of teenage childbearing, Demography, 1993, 30(1):1-13.

45. Geronimus AT, Teenage childbearing and social and reproductive disadvantage: the evolution of complex questions and the demise of simple answers, Family Relations, 1991, 40(4):463-471.

46. Furstenberg FF, Jr., Brooks-Gunn J and Morgan SP, Adolescent mothers and their children in later life, Family Planning Perspectives, 1987, 19(4):142-151. 
47. Brady SS and Halpern-Felsher BL, Adolescents' reported consequences of having oral sex versus vaginal sex, Pediatrics, 2007, $119(2): 229-236$.

48. Panchaud $C$ et al., Sexually transmitted diseases among adolescents in developed countries, Family Planning Perspectives, 2000, 32(1):24-32 \& 45.

49. Singh $S$ and Darroch JE, Adolescent pregnancy and childbearing: levels and trends in developed countries, Family Planning Perspectives, 2000, 32(1):14-23.

\section{Acknowledgments}

The project on which this article is based was supported by the Carolina Population Center, National Institute of Child Health and Human Development National Research Service Award predoctoral traineeship, grant NIH-NICHD T32-HD07168. An earlier version of this article was presented at the annual meeting of the Population Association of America, New York, Mar. 29-31, 2007. The authors thank Amy Schalet for her comments on an early manuscript version. This research uses data from Add Health, a program project designed by J. Richard Udry, Peter S. Bearman and Kathleen Mullan Harris, and funded by a grant P01-HD31921 from the Eunice Kennedy Shriver National Institute of Child Health and Human Development, with cooperative funding from 17 other agencies. Special acknowledgment is due Ronald R. Rindfuss and Barbara Entwisle for assistance in the original design. Persons interested in obtaining data files from Add Health should contact Add Health, Carolina Population Center, 123 W. Franklin Street, Chapel Hill, NC 27516-2524, or <addhealth@unc.edu>. No direct support was received from grant P01-HD31921 for this analysis.

Author contact: spriggs@email.unc.edu 